\title{
CRESCIMENTO E PRODUČ̃̃O DE GRÃOS DA SOJA SOB DIFERENTES DOSES E FONTES DE FÓSFORO EM SOLOS DISTINTOS
}

\author{
Soybean growth and yield under different doses and sources of phosphorus on distinct soils
}

\author{
Francisco Nildo da Silva', Antônio Eduardo Furtini Neto², Leandro Flávio Carneiro ${ }^{3}$, \\ Ciro Augusto de Souza Magalhães ${ }^{4}$, Daniella Nogueira Moraes Carneiro ${ }^{5}$
}

\begin{abstract}
RESUMO
A fertilidade dos solos das regiões tropicais é limitada pela baixa disponibilidade de fósforo e pela indisponibilização de boa parte do mesmo fornecido na adubação. Ainda existem muitas divergências sobre a melhor forma de utilização das diversas fontes fosfatadas disponíveis no Brasil. Objetivou-se, neste experimento, avaliar a produção de soja, sob a aplicação de diferentes doses e adubos fosfatados em dois tipos de solo. O trabalho foi realizado em casa de vegetação do Departamento de Ciência do Solo da Universidade de Lavras, em vasos de $3 \mathrm{dm}^{3}$. Utilizaram-se dois solos sob cerrado: Neossolo Quartzarênico e Latossolo Vermelho Distroférrico típico. Foram testadas oito fontes (superfosfato triplo-ST, termofosfato magnesiano-TF, quatro fosfatos reativos importados: FR1, FR2, FR3 e FR4 e dois fosfatos naturais nacionais- FN1 e FN2) e quatro doses $\left(0,100,300\right.$ e $\left.600 \mathrm{mg} \mathrm{dm}^{-3}\right)$ de fósforo, utilizando-se a soja como planta-teste. As fontes de solubilidade mais elevada ocasionaram as maiores produções e índices de eficiência em relação aos fosfatos naturais. Os fosfatos naturais importados e o FN2 apresentaram-se mais promissores em fornecer P para a cultura da soja, em relação ao superfosfato triplo, mesmo no primeiro cultivo, principalmente em solo com maior poder tampão de fósforo. A capacidade tampão de fósforo dos solos influenciou a eficiência das fontes de fósforo na cultura da soja.
\end{abstract}

Termos para indexação: Fontes de fósforo, solubilidade de fosfatos, eficiência agronômica.

\section{ABSTRACT}

The fertility of soils in tropical areas is limited by the low availability of phosphorus as well as by the unavailability of a great proportion of phosphorus supplied with fertilization. There are still some divergences about the best way of using the different sources of phosphorus available in Brazil. The aim of this experiment was to evaluate the soybean production as a result of the application of different phosphorous doses and fertilizers on two types of soils. The work was carried out in a greenhouse at Soil Science Department, Federal University of Lavras, in vases of $3 \mathrm{dm}^{3}$ using two kinds of soils: Dystroferric Red Latosol and Quartzarenic Neosols. Eight sources (triple superphosphate-TF, four foreign reactive rock phosphate: FR1, FR2, FR3, and FR4 and two national rock phosphate - FN1 and FN2) and four doses $\left(0,100,300\right.$, and $\left.600 \mathrm{mg} \mathrm{dm}^{-3}\right)$ were applied. Soybeans were used as test plant. Sources with higher solubility showed the highest production and efficiency than natural phosphate. The natural phosphate imported from other countries and FN2 showed good results in supplying $\mathrm{P}$ for the soybeans, when compared to the triple superphosphate, even at the first year of culture, mainly on the soil with higher P buffer power. The phosphorus buffer capacity of the soils affected the efficiency of phosphorus sources on the soybean culture.

Index terms: Phosphorus sources, phosphate solubility, agronomic efficiency.

\section{(Recebido em 12 de abril de 2007 e aprovado em 10 de outubro de 2008)}

\section{INTRODUÇÃO}

Um dos fatores responsáveis pela baixa disponibilidade de fósforo $(\mathrm{P})$, nos solos das regiões tropicais, é o fenômeno de fixação do $\mathrm{P}$ em reações com componentes do solo, necessitando, portanto, da aplicação de maiores quantidades de fosfatos para viabilizar o uso agrícola desses solos (RAIJ, 1991). Deve-se considerar que as reservas de rochas fosfatadas de boa qualidade no país são praticamente ausentes, o que aliado aos altos custos desses fertilizantes e o fato de que o nutriente é um recurso não renovável (PROCHNOW et al., 2003), justificam-se estudos para otimizar a eficiência no uso de fertilizantes fosfatados.

\footnotetext{
'Engenheiro Agrônomo, Doutor em Solos e Nutrição de Plantas - Departamento de Ciências Ambientais/DCA - Universidade Federal Rural do Semiárido/UFERSA - Br 110, Km 47 - Presidente Costa e Silva Mossoró, RN - 59626-900 - fnildo@ufersa.edu.br 2Professor Associado, Departamento de Ciência do Solo/DCS - Universidade Federal de Lavras/UFLA - Cx. P. 3037 - $37200-000$ - Lavras, MG afurtini@ufla.br

${ }^{3}$ Engenheiro Agrônomo, Doutorando em Ciência do Solo - Departamento de Ciência do Solo/DCS - Universidade Federal de Lavras/UFLA - Campus Universitário - Cx. P. 3037 - 37200-000 - Lavras, MG - leoflacar@yahoo.com.br

${ }^{4}$ Engenheiro Agrícola, Mestre em Ciência do Solo - Departamento de Ciência do Solo/DCS - Universidade Federal de Lavras/UFLA - Cx. P. 3037 37200-000 - Lavras, MG - ciroasm@yahoo.com.br

${ }^{5}$ Engenheira Agrônoma, Mestranda em Fitotecnia - Departamento de Agricultura/DAG - Universidade Federal de Lavras/UFLA - Campus Universitário Cx. P. 3037 -37200-000 - Lavras, MG - daninog27@yahoo.com.br
} 
Ainda existem muitas divergências sobre a melhor forma de utilização das diversas fontes fosfatadas disponíveis no país. Na avaliação da eficiência é importante levar-se em consideração, aspectos relacionados com o fertilizante (solubilidade e dose, por exemplo) e com variáveis relacionadas ao sistema solo-planta (PROCHNOW et al., 2003; SOUSA et al., 2002; COSTA et al., 2008).

Os fosfatos solúveis reagem com maior intensidade no solo, incrementando a fração de $\mathrm{P}$ disponível no solo, favorecendo a absorção pelas raízes. Porém, as reações de fixação do nutriente são também favorecidas, principalmente com aplicação de altas doses (favorecendo o solo) em solos oxídicos, ácidos e intemperizados o que reduz a sua eficiência ao longo do tempo e ainda são de alto custo. Já os fosfatos naturais liberam o nutriente de forma mais lenta, minimizando o processo de fixação (NOVAIS \& SMYTH, 1999; PROCHNOW et al., 2003; RESENDE et al., 2006; LANA et al., 2007).

O uso de termofosfatos (TF) implica na adição de quantidade expressiva de silício (Si), que, segundo Tisdale et al. (1993), uma maior quantidade de silicato no solo pode aumentar a disponibilidade de $\mathrm{P}$ devido à competição com os fosfatos, pelos sítios carregados positivamente nos óxidos de ferro e alumínio.

O fator capacidade de P (FCP) dos solos exerce grande influência sobre a eficiência agronômica dos fertilizantes fosfatados. Solos que possuem maior capacidade de fixação (elevado FCP), caso daqueles mais argilosos, apresentam menor disponibilidade do $\mathrm{P}$ proveniente do fertilizante, isto é, necessitam de maiores quantidades de fertilizantes fosfatados para se obter determinada concentração de $\mathrm{P}$, na solução do solo (NOVAIS \& SMYTH, 1999).

Por outro lado, solos com maior FCP podem estimular a solubilização dos fosfatos naturais (maior remoção de Ca e $\mathrm{P}$ nos sítios de dissolução), o que não significa aumento de eficiência, uma vez que o próprio solo pode indisponibilizar o P liberado (NOVAIS \& SMYTH, 1999). No caso dos fertilizantes solúveis, logo após a aplicação, o P pode ser rapidamente adsorvido pelo solo ou precipitado, formando compostos de menor solubilidade (LOPES \& GUILHERME, 1992).

É preciso considerar ainda, que espécies com alta demanda de cálcio e com a capacidade de complexar esse nutriente, devido à abundância em suas raízes de agentes complexantes como citratos e oxalatos, podem também ter alta eficiência de absorção de fósforo dos fosfatos naturais, pois essas características auxiliam na dissolução da apatita (MARWAHA, 1989). Segundo Marschner (1991), a soja tem grande capacidade de absorção de $\mathrm{Ca}$, o que desloca o equilíbrio da reação de dissolução da rocha fosfatada, aumentando a absorção de fósforo.
Objetivou-se, neste trabalho, avaliar a resposta em produção de matéria seca foliar e de grãos de soja à adubação fosfatada com diferentes fontes e doses de fósforo, em dois solos com atributos distintos originalmente sob vegetação de cerrado.

\section{MATERIAL E MÉTODOS}

O trabalho foi realizado em casa de vegetação do Departamento de Ciência do Solo da Universidade Federal de Lavras, no período de dezembro 2003 a maio de 2004. Utilizaram-se amostras da camada superficial $(0-20 \mathrm{~cm})$ de dois solos distintos: Neossolo Quartzarênico (RQo) e Latossolo Vermelho Distroférrico típico (LVdf). Os solos estudados foram coletados na região sul do Estado de Minas Gerais e seus atributos constam da Tabela 1.

Para cada solo foi conduzido um experimento. No RQo, o delineamento foi inteiramente casualizado com quatro repetições, em esquema fatorial $8 \times 4$, sendo oito fontes de P (superfosfato triplo - ST, termofosfato magnesiano - TF, quatro fosfatos reativos importados: FR1, FR2, FR3 e FR4 e dois fosfatos naturais nacionais FN1 e FN2) e quatro doses de $\mathrm{P}\left(0,100,300\right.$ e $\left.600 \mathrm{mg} \mathrm{dm}^{-3}\right)$. Para o LVdf, o delineamento experimental foi inteiramente casualizado, arranjado em fatorial $5 \times 4$, sendo 5 fontes de $\mathrm{P}$ (ST, TF, dois fosfatos naturais importados: FR3 e FR4 e um fosfato natural nacional - FN2) e quatro doses de $\mathrm{P}(0,100$, 300 e $600 \mathrm{mg} \mathrm{dm}^{-3}$ ), com quatro repetições. A quantidade aplicada de cada fonte foi calculada com base no teor de $\mathrm{P}_{2} \mathrm{O}_{5}$ total dos fertilizantes (Tabela 2), sendo todo o fósforo aplicado antes do plantio.

Tabela 1 - Principais atributos dos solos antes da aplicação dos tratamentos.

\begin{tabular}{|c|c|c|}
\hline & RQo & LVdf \\
\hline $\mathrm{pH}\left(\mathrm{H}_{2} \mathrm{O}\right)$ & 5,0 & 4,7 \\
\hline$P\left(\mathrm{mg} \mathrm{dm}^{-3}\right)$ & 2,8 & 0,6 \\
\hline $\mathrm{K}\left(\mathrm{cmol}_{\mathrm{c}} \mathrm{dm}^{-3}\right)$ & 8 & 8 \\
\hline $\mathrm{Ca}\left(\mathrm{cmol}_{\mathrm{c}} \mathrm{dm}^{-3}\right)$ & 0,4 & 0,4 \\
\hline $\operatorname{Mg}\left(\mathrm{cmol}_{\mathrm{c}} \mathrm{dm}^{-3}\right)$ & 0,1 & 0,2 \\
\hline $\mathrm{Al}\left(\mathrm{cmol}_{\mathrm{c}} \mathrm{dm}^{-3}\right)$ & 0,7 & 0,8 \\
\hline $\mathrm{H}+\mathrm{Al}\left(\mathrm{cmol}_{\mathrm{c}} \mathrm{dm}^{-3}\right)$ & 2,9 & 6,3 \\
\hline Matéria orgânica $\left(\mathrm{g} \mathrm{kg}^{-1}\right)$ & 8 & 25 \\
\hline $\mathrm{T}\left(\mathrm{cmol}_{\mathrm{c}} \mathrm{dm}^{-3}\right)$ & 3,4 & 6,9 \\
\hline $\mathrm{V}(\%)$ & 15,2 & 9,0 \\
\hline $\mathrm{Fe}\left(\mathrm{mg} \mathrm{dm}^{-3}\right)$ & 88,0 & 54,0 \\
\hline $\mathrm{Zn}\left(\mathrm{mg} \mathrm{dm}^{-3}\right)$ & 0,4 & 1,5 \\
\hline $\mathrm{P}$ - remanescente $\left(\mathrm{mg} \mathrm{L}^{-1}\right)$ & 34,7 & 12,2 \\
\hline $\operatorname{Areia}\left(\mathrm{g} \mathrm{kg}^{-1}\right)$ & 900 & 150 \\
\hline Silte $\left(\mathrm{g} \mathrm{kg}^{-1}\right)$ & 30 & 100 \\
\hline Argila $\left(\mathrm{g} \mathrm{kg}^{-1}\right)$ & 70 & 750 \\
\hline
\end{tabular}

Análises realizadas segundo metodologia da Embrapa (1997). 
Para a correção da acidez dos solos foi utilizado calcário dolomítico (PRNT $=100 \%$ ), incubado por um mês antes do plantio, para elevar a saturação por bases a $60 \%$. Todos os tratamentos receberam como adubação básica, $50 \mathrm{mg} \mathrm{dm}^{-3}$ de $\mathrm{N}$ (sulfato de amônio), $60 \mathrm{mg} \mathrm{dm}^{-3}$ de $\mathrm{K}$ (sulfato de potássio), 0,5 $\mathrm{mg} \mathrm{dm}^{-3}$ de B (ácido bórico), 1,5 $\mathrm{mg} \mathrm{dm}{ }^{-3} \mathrm{de} \mathrm{Cu}$ (sulfato de cobre), $5 \mathrm{mg} \mathrm{dm}^{-3}$ de $\mathrm{Zn}$ (sulfato de zinco), $5 \mathrm{mg} \mathrm{dm}^{-3}$ de Fe (sulfato de ferro) e $3,6 \mathrm{mg} \mathrm{dm}^{-3}$ de Mn (sulfato de manganês).

Tabela 2 - Fósforo total e solubilidade em ácido cítrico dos fertilizantes fosfatados.

\begin{tabular}{|c|c|c|c|}
\hline \multirow[t]{2}{*}{ Fonte } & \multirow[t]{2}{*}{ Sigla } & $\begin{array}{l}\mathrm{P}_{2} \mathrm{O}_{5} \\
\text { Total } \\
\end{array}$ & $\begin{array}{c}\mathrm{P}_{2} \mathrm{O}_{5} \mathrm{em} \\
\text { ácido cítrico } \\
\end{array}$ \\
\hline & & \multicolumn{2}{|c|}{-----------------\%------ } \\
\hline $\begin{array}{l}\text { Superfosfato } \\
\text { triplo }\end{array}$ & ST & 46,1 & 40,0 \\
\hline Termofosfato & $\mathrm{TF}$ & 18,1 & 17,6 \\
\hline $\begin{array}{l}\text { Fosfato } \\
\text { reativo } 1\end{array}$ & FR1 & 33,1 & 9,7 \\
\hline $\begin{array}{l}\text { Fosfato } \\
\text { reativo } 2\end{array}$ & FR2 & 28,5 & 13,0 \\
\hline $\begin{array}{l}\text { Fosfato } \\
\text { reativo } 3\end{array}$ & FR3 & 32,0 & 9,8 \\
\hline $\begin{array}{l}\text { Fosfato } \\
\text { reativo } 4\end{array}$ & FR4 & 29,0 & 9,0 \\
\hline $\begin{array}{l}\text { Fosfato } \\
\text { natura1 } 1\end{array}$ & FN1 & 24,0 & $\mathrm{Nd}$ \\
\hline $\begin{array}{l}\text { Fosfato } \\
\text { natural } 2\end{array}$ & FN2 & 22,7 & 4,3 \\
\hline
\end{tabular}

Nd: não determinado

Após a aplicação dos tratamentos, procedeu-se à semeadura de seis sementes de soja, cultivar Monsoy 8400 , mantendo-se, por meio de desbaste, três plantas no vaso de $3 \mathrm{dm}^{3}$. Durante o período de condução dos experimentos, a umidade foi controlada diariamente por meio de irrigação com água deionizada. Adubações de cobertura, utilizandose sulfato de amônio, nitrato de potássio e nitrato de amônio, foram divididas em quatro aplicações, para todos os tratamentos, totalizando $110 \mathrm{mg} \mathrm{dm}^{-3} \mathrm{de} \mathrm{S} ; 150 \mathrm{mg} \mathrm{dm}^{-3}$ $\mathrm{K}$ e de $230 \mathrm{mg} \mathrm{dm}^{-3}$ de $\mathrm{N}$.

No início do florescimento da soja (60 DAP), foi colhida a parte aérea de uma planta de cada parcela, deixando-se apenas duas plantas por vaso. Esse material foi seco em estufa, sendo posteriormente triturado e submetido a análises químicas (MALAVOLTA et al., 1997).
Conduziu-se a soja até o final do ciclo, ocasião em que a parte aérea das plantas remanescentes foi colhida, sendo os grãos manualmente retirados das vagens para avaliação da produção de matéria seca. Caules e vagens foram secos em estufa, juntamente com as folhas que senesceram e caíram ao longo do ciclo, a fim de determinar a produção de matéria seca da parte aérea (MSPA) e matéria seca dos grãos (MSG).

A eficiência dos fertilizantes fosfatados foi avaliada por meio do índice de eficiência agronômica (IEA), calculada através da relação porcentual entre a produtividade propiciada pelas fontes de $\mathrm{P}$, aplicada na dose correspondente à produção máxima (PM) de cada fonte, subtraindo-se de ambos a produtividade do tratamento sem adubação fosfatada, conforme descrito por Goedert et al. (1986), sendo calculada da seguinte forma:

$$
\operatorname{IEA}(\%)=(\mathrm{Y} 2-\mathrm{Y} 1 / \mathrm{Y} 3-\mathrm{Y} 1) \times 100
$$

Onde: $\mathrm{Y} 1$ = Produtividade obtida pelo tratamento em que não houve aplicação de fósforo; Y2 = Produtividade obtida pela fonte que está sendo testada; e Y3 = Produtividade obtida pela fonte referência (superfosfato triplo).

Os dados experimentais foram submetidos à análise de variância e de regressão com auxílio do programa estatístico Sisvar (FERREIRA, 2000). A partir dos modelos de regressão foram estimadas as doses de $\mathrm{P}$, para a obtenção da produção máxima (PM) da parte aérea e dos grãos e suas doses equivalentes. Quando o ajuste foi linear, adotou-se a maior dose aplicada como equivalente à dose de PM.

\section{RESULTADOS E DISCUSSÃO}

Ocorreu efeito da interação fontes $\mathrm{x}$ doses de fósforo para a produção de MSPA e MSG nos dois solos estudados $(\mathrm{p}<0,05)$.

Os fosfatos nacionais promoveram um ajuste ao modelo linear, para a produção de MSPA, não alcançando a máxima produção com as doses aplicadas, tanto no RQo quanto no LVdf. Em relação à produção de MSG, todas as fontes de $\mathrm{P}$ promoveram ajuste quadrático com o aumento das doses de P, nos solos estudados (Tabela 3).

$\mathrm{O}$ ajuste ao modelo linear para a produção de MSPA, nos solos estudados, com a aplicação de fosfatos naturais, pode ser explicado pela baixa solubilidade desses fosfatos, levando à necessidade de altas doses de $\mathrm{P}$ para atingir a máxima produção. Coutinho et al. (1991) observaram menor produção de grãos de soja com o uso do fosfato natural de Patos de Minas em relação ao ST, TF e fosfato reativo de Gafsa. O fator que se deve considerar na eficiência desses fosfatos é o tempo de cultivo. Resende et al. (2006) estudaram fontes de fósforo para o milho, em solo cultivado 
Tabela 3 - Equações de regressão para a produção de matéria seca da parte aérea e matéria seca de grãos $\left(\mathrm{g}\right.$ vaso $\left.{ }^{-1}\right)$, em função das doses e fontes de fósforo aplicadas $\left(\mathrm{mg} \mathrm{dm}^{-3}\right)$ nos solos estudados.

\begin{tabular}{|c|c|c|c|}
\hline Tipo solo & Fonte de $\mathrm{P}$ & Equação & $\mathrm{R}^{2}$ \\
\hline \multicolumn{4}{|c|}{ Matéria seca da parte aérea } \\
\hline \multirow{8}{*}{ Rqo } & FR1 & $\mathrm{y}=3,19+1,56 * * x^{0,5}-0,020 * * x$ & 0,94 \\
\hline & FR2 & $\mathrm{y}=3,49+1,67 * * \mathrm{x}^{0,5}-0,034 * * \mathrm{x}$ & 0,99 \\
\hline & FR4 & $\mathrm{y}=5,07+1,42 * * x^{0,5}-0,033 * * x$ & 0,99 \\
\hline & FR3 & $\mathrm{y}=4,07+1,28 * * x^{0,5}-0,013 * * x$ & 0,99 \\
\hline & FN1 & $\mathrm{y}=2,440+0,01003 * * x$ & 0,86 \\
\hline & FN2 & $\mathrm{y}=3,836+0,03320 * * \mathrm{x}$ & 0,89 \\
\hline & ST & $\mathrm{y}=4,73+4,16 * * x^{0,5}-0,144 * * x$ & 0,94 \\
\hline & $\mathrm{TF}$ & $y=3,92+2,96 * * x^{0,5}-0,061 * * x$ & 0,93 \\
\hline C.V. $(\%)$ & \multicolumn{3}{|c|}{22,5} \\
\hline \multirow{5}{*}{ LVdf } & FN2 & $\mathrm{y}=4,313+0,04290 * * x$ & 0,94 \\
\hline & FR3 & $\mathrm{y}=0,55+1,93 * * x^{0,5}-0,031 * * x$ & 0,96 \\
\hline & FR4 & $\mathrm{y}=0,54+2,74 * * x^{0,5}-0,063 * * x$ & 0,95 \\
\hline & ST & $\mathrm{y}=1,45+2,92 * * \mathrm{x}^{0,5}-0,048 * * \mathrm{x}$ & 0,99 \\
\hline & $\mathrm{TF}$ & $y=2,23+2,18 * * x^{0,5}-0,004 * * x$ & 0,99 \\
\hline C.V. $(\%)$ & \multicolumn{3}{|c|}{25,3} \\
\hline \multicolumn{4}{|c|}{ Matéria seca de grãos } \\
\hline \multirow{8}{*}{ RQo } & FR1 & $\mathrm{y}=1,66+0,47 * * x^{0,5}-0,0006 * * x$ & 0,95 \\
\hline & FR2 & $\mathrm{y}=2,56+0,44 * x^{0,5}-0,0009 * * x$ & 0,92 \\
\hline & FR3 & $\mathrm{y}=2,02+0,68 * * x^{0,5}-0,009 * * x$ & 0,96 \\
\hline & FR4 & $y=0,99+0,76^{* *} x^{0,5}-0,012 * * x$ & 0,95 \\
\hline & FN1 & $\mathrm{y}=1,29+0,54 * * x^{0,5}-0,014 * * x$ & 0,74 \\
\hline & FN2 & $\mathrm{y}=1,81+0,62 * * x^{0,5}-0,011 * * x$ & 0,98 \\
\hline & ST & $\mathrm{y}=1,66+1,65 * * \mathrm{x}^{0,5}-0,051 * * \mathrm{x}$ & 1,00 \\
\hline & TF & $\mathrm{y}=1,63+1,73 * * x^{0,5}-0,041 * * x$ & 1,00 \\
\hline C.V $(\%)$ & \multicolumn{3}{|c|}{22,5} \\
\hline \multirow{5}{*}{ LVdf } & FN2 & $\mathrm{y}=1,50+0,74 * * x^{0,5}-0,004 * * x$ & 0,99 \\
\hline & FR3 & $\mathrm{y}=0,43+1,13 * * \mathrm{x}^{0,5}-0,017 * * \mathrm{x}$ & 0,98 \\
\hline & FR4 & $\mathrm{y}=2,048+1,23 * * x^{0,5}-0,027 * * x$ & 0,95 \\
\hline & ST & $\mathrm{y}=1,04+1,93 * * x^{0,5}-0,045^{* * x}$ & 0,99 \\
\hline & TF & $\mathrm{y}=1,44+1,61 * * x^{0,5}-0,03180 * * x$ & 0,99 \\
\hline
\end{tabular}

FR1: Fosfato reativo 1; FR2: Fosfato reativo 2; FR3: Fosfato reativo 3; FR4: Fosfato reativo 4; FN1: Fosfato natural 1; FN2: Fosfato natural 2; ST: Superfosfato triplo; TF: Termofosfato.

* e ** Significativo, a 5 e $1 \%$ de probabilidade respectivamente, pelo teste $\mathrm{t}$.

da região do cerrado e concluíram que o fosfato de Araxá equiparou-se às fontes mais solúveis no terceiro cultivo, em condições de campo.

$\mathrm{Na}$ Tabela 4, são apresentadas as produções máximas (PM) de MSPA e MSG, estimadas a partir dos modelos de regressão, em função de doses e fontes de $\mathrm{P}$ aplicados e o índice de eficiência agronômica (IEA) das fontes de $\mathrm{P}$, avaliada pela produção de grãos nos solos utilizados.

A aplicação de termofosfato (TF) resultou em maior produção de MSPA, MSG e IEA nos dois solos estudados 
(Tabela 4). Bedin (2002) encontrou produção relativa de 116\% de MSPA de soja em relação ao tratamento referência (ST + calcário dolomítico) para o TF. Gava et al. (1997) também encontraram na produção de mudas de eucalípto, para o TF, superioridade da ordem de $64 \%$ do índice de eficiência relativa ao superfosfato simples, em um Neossolo Quartzarênico. O fato do termofosfato constituir-se em um fertilizante mais completo, possuindo em sua composição, além do fósforo, magnésio e micronutrientes, certamente explica o melhor comportamento do fertilizante em relação ao tratamento referência.

Segundo Araújo (2001), essa superioridade do TF pode ser explicada em função do processo tecnológico de obtenção dessa fonte de $\mathrm{P}$, o qual não apresenta restrição quanto à pureza da matéria-prima empregada e também por apresentar efeitos benéficos, como a elevação do pH e

Tabela 4 - Estimativa das produções máximas (PM) $\left(\mathrm{g}\right.$ vaso $\left.^{-1}\right)$ de matéria seca da parte aérea, matéria seca de grãos, doses de $\mathrm{P}$ correspondentes a essas produções e índice de eficiência agronômica (IEA) das fontes de P, avaliada pela produção de grãos nos solos estudados.

\begin{tabular}{|c|c|c|c|c|}
\hline Solo & Fonte & Dose de $\mathrm{P}\left(\mathrm{mg} \mathrm{dm}^{-3}\right)$ & PM $\left(\right.$ g vaso $\left.^{-1}\right)$ & \\
\hline \multicolumn{5}{|c|}{ Matéria seca da parte aérea } \\
\hline \multirow{8}{*}{ RQo } & ST & 209 & 34,77 & \\
\hline & $\mathrm{TF}$ & 589 & 39,83 & \\
\hline & FR1 & 600 & 29,40 & \\
\hline & FR2 & 600 & 24,00 & \\
\hline & FR3 & 600 & 27,62 & \\
\hline & FR4 & 463 & 20,35 & \\
\hline & FN1 & 600 & 3,44 & \\
\hline & FN2 & 600 & 23,76 & \\
\hline \multirow{6}{*}{$\mathrm{LVdf}$} & ST & 600 & 44,17 & \\
\hline & $\mathrm{TF}$ & 600 & 53,23 & \\
\hline & FN2 & 600 & 30,05 & \\
\hline & FR3 & 600 & 29,23 & \\
\hline & FR4 & 473 & 30,33 & \\
\hline & \multicolumn{3}{|c|}{ Matéria seca de Grãos (g vaso $\left.{ }^{-1}\right)$} & IEA* $(\%)$ \\
\hline \multirow{8}{*}{ RQo } & ST & 262 & 15,01 & 100 \\
\hline & $\mathrm{TF}$ & 455 & 19,88 & 163 \\
\hline & FR1 & 600 & 12,81 & 85 \\
\hline & FR2 & 600 & 12,80 & 80 \\
\hline & FR3 & 600 & 13,28 & 76 \\
\hline & FR4 & 600 & 12,41 & 78 \\
\hline & FN1 & 372 & 6,50 & 28 \\
\hline & FN2 & 600 & 10,40 & 57 \\
\hline \multirow{5}{*}{ LVdf } & ST & 460 & 21,73 & 100 \\
\hline & $\mathrm{TF}$ & 600 & 21,80 & 100 \\
\hline & FN2 & 600 & 17,15 & 75 \\
\hline & FR3 & 600 & 17,91 & 82 \\
\hline & FR4 & 519 & 16,06 & 73 \\
\hline
\end{tabular}

* IEA = índice de eficiência agronômica Goedert et al. (1986), considerando o superfosfato triplo como referência, ao qual se atribuiu o índice de $100 \%$ para a produção de grão.

FR1: Fosfato reativo 1; FR2: Fosfato reativo 2; FR3: Fosfato reativo 3; FR4: Fosfato reativo 4; FN1: Fosfato natural 1; FN2: Fosfato natural 2; ST: Superfosfato triplo; TF: Termofosfato. 
dos teores de $\mathrm{Ca}, \mathrm{Mg}$, Si e alguns micronutrientes. Porém, é preciso atentar para a eficiência econômica desse fosfato. Resende et al. (2006), analisando a eficiência econômica de produção de grãos, na cultura do milho, concluíram que, embora associado à obtenção de boas produtividades, o TF foi a fonte de menor vantagem econômica devido ao custo proporcionalmente mais elevado em relação às demais fontes.

Entre os fosfatos reativos, no RQo, o FR1 proporcionou maior produção de MSPA (29,4 g.vaso ${ }^{-1}$ na dose correspondente a $600 \mathrm{mg} \mathrm{dm}^{-3}$ de P) e IEA $(85 \%$ em relação ao ST). Para os demais fosfatos reativos (FR2, FR3 e FR4, no RQo e FR3 e FR4, no LVdf), a produção de MSPA foi semelhante, porém com maiores valores no LVdf, provavelmente devido ao maior fator capacidade de $\mathrm{P}$ (mais argiloso) desse solo, favorecendo uma maior remoção de Ca e P nos sítios de dissolução e consequentemente sua dissolução (NOVAIS \& SMYTH , 1999). A produção de MSG teve o mesmo comportamento, exceto para o FR1, e o IEA, para esses fosfatos variou de $76 \%$ a $85 \%$ nos solos em estudo (Tabela 4). Uma menor solubilidade dos fosfatos reativos em relação às fontes mais solúveis(ST e TM), certamente pode explicar o menor IEA dessas fontes de fósforo, e, suas diferenças, são reflexo da própria natureza química de cada fonte individual.

Experimento em solo de cerrado mostrou que o fosfato reativo da Carolina do Norte moído ( $85 \%$ das partículas menores do que $0,074 \mathrm{~mm}$ ), teve eficiência equivalente ao ST no primeiro plantio de soja (PERUZZO et al., 1997), indicando que a utilização de fosfatos reativos (importados) parece ser uma alternativa promissora para o fornecimento de $\mathrm{P}$ para as culturas, por apresentarem maior solubilidade em relação aos nacionais (Tabela 2). A maior solubilidade dos fosfatos reativos é explicada por serem derivados de rochas de origem sedimentar, apresentando elevado grau de substituição de fosfatos por carbonatos e consequentemente menor cristalização (KAMINSKI \& PERUZZO, 1997).

No caso dos fosfatos naturais nacionais, o FN2 proporcionou maior produção de MSPA, MSG e IEA em relação ao FN1, no RQo. No LVdf, os resultados de produção de MSPA, MSG e IEA, com a aplicação do FN2, foram semelhantes aos fosfatos reativos importados (Tabela 4). Existe grande variabilidade dos fosfatos naturais em relação à solubilidade e aos teores de fósforo. Essa variabilidade é decorrente de características intrínsecas às rochas, como o grau de substituição isomórfica de fosfatos por carbonatos e da granulometria dos fosfatos (HOROWITZ \& MEURER, 2003; RAJAN et al., 1996).
A respeito do menor IEA dos fosfatos naturais importados e nacionais em relação às fontes solúveis(Tabela 4), cabe ressaltar que o IEA foi calculado em apenas um cultivo da soja e os fosfatos naturais têm um maior efeito residual com o tempo (MCLAUGHLIN et al., 1992). Apesar da tendência de apresentarem menor efetividade em termos agronômicos, as fontes menos solúveis podem ser economicamente mais viáveis. Resende et al. (2006), observaram que, dependendo do modo de aplicação, o uso do fosfato de Araxá resultou em relação benefício/custo duas vezes mais compensadora do que a obtida com o ST.

A melhor eficiência da aplicação de $\mathrm{P}$ foi encontrada no RQo, para as fontes mais solúveis (ST e TF), diferentemente do FR3, FR4 e FN2, os quais obtiveram maior produção de MSG, por unidade de $\mathrm{P}$ no LVdf (Tabela 5).

Tabela 5 - Produção de matéria seca de grãos (MSG) da soja por unidade de $\mathrm{P}$ aplicada para cada fertilizante fosfatado, em solos distintos na dose de máxima produção.

\begin{tabular}{ccc}
\hline Fonte & RQo & LVdf \\
\hline & $--------m g$ MSG por mg P aplicado------- \\
\hline ST & 19,10 & 15,75 \\
TF & 14,89 & 12,11 \\
FN2 & 5,78 & 9,52 \\
FR3 & 7,37 & 9,95 \\
FR4 & 6,89 & 10,31 \\
\hline
\end{tabular}

Esses resultados indicam que o melhor desempenho das fontes mais solúveis está relacionado com a menor capacidade tampão para fósforo do solo (menor fixação de P). No caso dos fosfatos naturais, solos mais argilosos favorecem o dreno de $\mathrm{P}$ dos sítios de dissolução, e consequentemente sua solubilidade (NOVAIS \& SMYTH, 1999). Tais evidências devem ser consideradas quando se busca um adequado manejo das fontes fosfatadas, refletindo-se certamente na rentabilidade do agricultor.

\section{CONCLUSÕES}

As fontes de solubilidade mais elevada (superfosfato triplo e termofosfato) proporcionaram as maiores produções de matéria seca e índice de eficiência, em relação aos fosfatos naturais.

Fosfatos naturais importados e o FN2 apresentaramse promissores em fornecer $\mathrm{P}$ para a cultura da soja, principalmente em solo com maior poder tampão de fósforo. 
Em solos com maior capacidade tampão a solubilidade das fontes menos solúveis é maior, sendo sensivelmente reduzida em solos com menor capacidade tampão de $\mathrm{P}$.

\section{REFERÊNCIAS BIBLIOGRÁFICAS}

ARAÚJO, I. B. Fontes e modos de aplicação de fósforo e nutrição mineral do milho em primeiro cultivo. 2001.76 p. Dissertação (Mestrado em Agronomia: Solos e Nutrição de Plantas) - Universidade federal de Lavras, Lavras, 2001.

BEDIN, I. Fertilização fosfatada na cultura da soja. 2002. 65 p. Dissertação (Mestrado em Agronomia: Solos e Nutrição de Plantas) - Universidade Federal de Lavras, Lavras, 2002.

COUTINHO, E. L. M.; NATALE, W.; VILLA NOVA, A. S.; SITTA, D. S. X. Eficiência agronômica de fertilizantes fosfatados para a cultura da soja. Pesquisa Agropecuária Brasileira, Brasília, v. 26, p. 1393-1399, 1991.

COSTA, S. E. V. G. DE A.; FURTINI NETO, A. E.; RESENDE, Á. V. DE; SILVA, T. O. DA; SILVA, T. R. DA. Crescimento e nutrição da braquiária em função de fontes de fósforo. Ciência e Agrotecnologia, Lavras, v. 32, n. 5, p. 1419-1427, set./out., 2008.

\section{EMPRESA BRASILEIRA DE PESQUISA}

AGROPECUÁRIA. Centro Nacional de Pesquisa de Solos. Manual de métodos de análise de solo. 2. ed. Rio de Janeiro, 1997.

FERREIRA, D. F. Análises estatísticas por meio do Sisvar para Windows versão 4.0. In: REUNIAO ANUAL DA REGIAO BRASILEIRA DA SOCIEDADE INTERNACIONAL DE BIOMETRIA, 45., 2000, São Carlos, SP. Programa e Resumos... São Carlos: UFScar, 2000. p. 255-258.

GAVA, J. L. et al. Eficiência relativa de fertilizantes fosfatados no crescimento inicial de eucalipto cultivado em solos do cerrado. Revista Brasileira de Ciência do Solo, Viçosa, v. 21, p. 497-504, 1997.

GOEDERT, W. J.; SOUZA, D. M. G.; REIN, T. A Principios metodólogicos para a avaliação agronomica de fontes de fosfóro. Planaltina: Embrapa-CPAC, 1986. 23 p. (Documento, 22).
HOROWITZ, N.; MEURER, E. J. eficiência de dois fosfatos naturais afetada pelo tamanho de partícula. Ciência Rural, Santa Maria, v. 33, n. 1, p. 41-47, 2003.

KAMINSKI, J.; PERUZZO, G. Eficácia de fosfatos naturais reativos em sistema de cultivo. Santa Maria: Núcleo Regional Sul da Sociedade Brasileira de Ciência do Solo, 1997. 31 p. (Boletim técnico, 3).

LANA, R. M. Q.; BUCK, G. B.; LANA, Â. M. Q.; PEREIRA, R. P. Doses de multifosfato magnesiano aplicados a lanço em pré-semeadura, sob sistema plantio direto Cultura da soja. Ciência e Agrotecnologia, Lavras, v. 31, n. 6, p. 1654-1660, nov./dez., 2007.

LOPES, A. S.; GUILHERME, L. R. G. Fertilizantes e corretivos agrícolas: sugestões de manejo para uso eficiente. In: REUNIÃO BRASILEIRA DE FERTILIDADE DO SOLO E NUTRIÇÃO DE PLANTAS, 20., 1992, Piracicaba, SP. Anais... Campinas: Fundação Cargill, 1992. p. 39-69.

MALAVOLTA, E.; VITTI, G. C.; OLIVEIRA, S. A. de. Avaliação do estado nutricional das plantas: princípios e aplicações. Piracicaba: Potafos, 1997. 210 p.

MARSCHNER, H. Root-induced changes in the avalability of micronutrients in the rhizosphere. In: WAISEL, Y.; ESHEL, A.; KAFKAFI, U. (Eds.). Plant roots: the hidden half. New York: M. Dekker, 1991. p. 503-528.

MARWAHA, B. C. Rock pHospHate holds the key to productivity in acid soils: a review. Fertilizer News, New Delhi, v. 34, n. 3, p. 23-29, 1989.

McLAUGHLIN, M. J. et al. Glasshouse comparison of North Carolina pHospHate rock, alkali-treated Christmas Island $\mathrm{pHospHate}$ rock and single superpHospHate as $\mathrm{P}$ fertilizers on an acidic soil. Australian Journal of Soil Research, Melbourne, v. 43, p. 1667-1681, 1992.

NOVAIS, R. F. de; SMYTH, T. J. Fósforo em solo e planta em condições tropicais. Viçosa, MG: UFV/DPS, 1999. $399 \mathrm{p}$.

PERUZZO, G.; POTTKER, D.; WIETHOLTER, S.

Avaliação da eficiência agronômica dos fosfatos naturais reativos de Arad e de Gafsa. In: CONGRESSO BRASILEIRO DE CIÊNCIAS DO SOLO, 26., 1997, Rio de Janeiro, RJ. Anais... Rio de Janeiro: SBCS, 1997. CD-ROM. 
PROCHNOW, L. I. et al. Characterization and agronomic evaluation of single superphosphates varying in iron phosphate impurities. Agronomy Journal, Madison, v. 95, p. 293-302, 2003.

RAIJ, B. van. Fertilidade do solo e adubação. Piracicaba: Potafos, 1991. 343 p.

RAJAN, S. S. S.; WATKINSON, J. H.; SINCLAIR, A. G. Phosphate rocks for direct application to soils. Advances in Agronomy, New York, v. 57, p. 77-159, 1996.

RESENDE, A. V.; FURTINI NETO, A. E.; ALVES, V. M. C.; MUNIZ, J. A.; CURI, N.; FAQUIN, V.; KIMPARA,
D. I.; SANTOS, J. Z. L.; CARNEIRO, L. F. Fontes e modos de aplicação de fósforo para o milho em solo cultivado da região do cerrado. Revista Brasileira de Ciência do Solo, Viçosa, v. 30, n. 3, p. 453-466, 2006.

SOUSA, D. M. G.; LOBATO, E.; REIN, T. A. Adubação com fósforo. In: SOUSA, D. M. G.; LOBATO, E. (Eds.). Cerrado: correção do solo e adubação. Planaltina: Embrapa Cerrados, 2002. p. 147-168.

TISDALE, S. L. et al. Soil fertility and fertilizers. New York: Macmmillan, 1993. 